\title{
On improvement in ejection fraction with iron chelation in thalassemia major and the risk of future heart failure
}

\author{
DJ Pennell ${ }^{1,2^{*}}$, JP Carpenter ${ }^{1,2}$, M Roughton $^{3}$ and ZI Cabantchik ${ }^{4}$
}

\begin{abstract}
Background: Trials of iron chelator regimens have increased the treatment options for cardiac siderosis in betathalassemia major (TM) patients. Treatment effects with improved left ventricular (LV) ejection fraction (EF) have been observed in patients without overt heart failure, but it is unclear whether these changes are clinically meaningful.

Methods: This retrospective study of a UK database of TM patients modelled the change in EF between serial scans measured by cardiovascular magnetic resonance (CMR) to the relative risk (RR) of future development of heart failure over 1 year. Patients were divided into 2 strata by baseline LVEF of 56-62\% (below normal for TM) and 63-70\% (lower half of the normal range for TM).

Results: A total of 315 patients with 754 CMR scans were analyzed. A 1\% absolute increase in EF from baseline was associated with a statistically significant reduction in the risk of future development of heart failure for both the lower EF stratum (EF 56-62\%, RR 0.818, $p<0.001$ ) and the higher EF stratum (EF 63-70\%, RR $0.893 p=0.001$ ).

Conclusion: These data show that during treatment with iron chelators for cardiac siderosis, small increases in LVEF in TM patients are associated with a significantly reduced risk of the development of heart failure. Thus the iron chelator induced improvements in LVEF of 2.6\% to 3.1\% that have been observed in randomized controlled trials, are associated with risk reductions of $25.5 \%$ to $46.4 \%$ for the development of heart failure over 12 months, which is clinically meaningful. In cardiac iron overload, heart mitochondrial dysfunction and its relief by iron chelation may underlie the changes in LV function.
\end{abstract}

\section{Background}

Major advances have been made in the last 10 years in the understanding and treatment of cardiac siderosis in beta-thalassaemia major (TM) patients. Those advances are attributable primarily to the development of a method for the quantification of myocardial iron based on magnetic resonance $\mathrm{T} 2 *$ imaging and its worldwide adoption,[1,2] which has permitted the recognition of the high prevalence of cardiac siderosis in patients chronically treated with deferoxamine, $[1,3,4]$ the establishment of the association of cardiac siderosis with impaired left ventricular ejection fraction (LVEF) [1,5-7] the identification of iron-chelation regimes which are

\footnotetext{
* Correspondence: d.pennell@ic.ac.uk

${ }^{1}$ Cardiovascular Magnetic Resonance Unit, Royal Brompton Hospital, London UK

Full list of author information is available at the end of the article
}

effective in removal of iron from the heart [8-12] and the reduction in cardiac mortality in populations[13-15]. Studies reporting on the use of iron chelators in treating transfusional iron overload have raised interesting questions with regard to cardiac efficacy relating to changes in the mean LVEF of the TM cohorts under study. Studies of TM patients in heart failure with severe cardiac siderosis and depressed LVEF show that combination treatment with deferiprone and deferoxamine increased mean absolute cohort LVEF by $14 \%$ over 1 year,[10] or treatment with continuous intravenous deferoxamine raised LVEF by $11 \%[16]$. Changes in LVEF of this magnitude accompanied with relief of heart failure have clear clinical benefit. However, in TM patients with mild to moderate cardiac siderosis, randomized controlled trials of deferiprone monotherapy raised the mean cohort absolute LVEF by $3.1 \%$,[8] whilst

\section{() Biomed Central}


deferiprone in combination with deferoxamine raised absolute LVEF by $2.6 \%[9]$. The clinical meaningfulness of these statistically significant but smaller improvements in LVEF is less clear. We therefore sought to determine the clinical significance of changes in LVEF from a UK database of TM patients by statistical modelling of the change in LVEF between serial scans to the future development of heart failure, which is an important clinical endpoint in TM associated with a high mortality[14,17].

\section{Methods}

Ethical permission was obtained from the research ethical committee for this study. A database of 652 patients from 21 UK haematology centres was established and maintained prospectively, as previously reported[18]. We approached the question of the clinical significance of changes in LVEF by determining the number of patients recorded in the database who had: a) at least 2 cardiovascular magnetic resonance (CMR) scans; b) LVEF measured by CMR at each time point and a baseline EF of $<71 \%$, which is the lower half of the normal range for thalassaemia major patients without cardiac iron loading;[19] c) complete clinical follow-up for the clinical outcome of heart failure for 12 months after each scan. Patients on all treatments and all baseline cardiac T2* values were included. The patient demographics are shown in table 1 . The primary outcome measure for this study was the development of symptomatic heart failure within 12 months of a CMR scan. A new diagnosis of heart failure was made only if the patient complained of worsening dyspnoea at rest or during exercise, objective LV dysfunction was present with an ejection fraction of $<56 \%,[1,9]$ and the caring clinician made the clinical diagnosis of heart failure.

Patients were scanned with a $1.5 \mathrm{~T}$ scanner (Sonata, Siemens Medical Solutions, Erlangen, Germany) using previously reported techniques[20]. In brief, CMR was performed with a cardiac gated, single breath-hold, 8echo sequence (2.6 to $16.7 \mathrm{~ms}$, increasing in $2.02-\mathrm{ms}$ increments) of a single mid-ventricular short-axis slice. Long-axis cines and a contiguous stack of short-axis cines were also acquired to assess left ventricular dimensions and function using standard techniques [21]. Data analysis was performed using CMRtools and its plug-in Thalassemia-Tools (Cardiovascular Imaging Solutions, London, UK) for the heart T2* (a large region of the interventricular septum excluding regions in proximity to the coronary veins), as well as left ventricular ejection fraction using semi-automated planimetry of endocardial borders[21]. All scans were reported at the time of acquisition by multiple operators, and a clinical report was generated for the referring physician.
Table 1 Demographics of the patients at the first qualifying scan for analysis.

\begin{tabular}{lcc}
\hline Baseline ejection fraction group & $\mathbf{5 6 \% - 6 2 \%}$ & $\mathbf{6 3 \% - 7 0 \%}$ \\
\hline $\mathrm{N}$ & 109 & 216 \\
Age & $26.6(8.6)$ & $26.6(8.7)$ \\
Sex & & \\
$\quad$ Male N (\%) & $59(54.1)$ & $110(53.4)$ \\
$\quad$ Female N (\%) & $50(45.9)$ & $96(46.6)$ \\
Ethnicity & & \\
$\quad$ Indian N (\%) & $31(28.4)$ & $56(27.2)$ \\
$\quad$ Greek N (\%) & $18(16.5)$ & $31(15.1)$ \\
$\quad$ Cypriot N (\%) & $17(15.6)$ & $30(14.6)$ \\
$\quad$ Pakistani/Bangladeshi N (\%) & $14(12.8)$ & $32(14.8)$ \\
$\quad$ Turkish/Arabic N (\%) & $12(11.0)$ & $18(8.3)$ \\
$\quad$ Italian/Romanian N (\%) & $6(5.5)$ & $12(5.6)$ \\
$\quad$ Chinese/Malay N (\%) & $5(4.6)$ & $4(2.0)$ \\
$\quad$ Unknown N (\%) & $7(6.4)$ & $20(9.3)$ \\
Ferritin [ug/L] & $2140(1600)$ & $2065(1636)$ \\
Cardiac T2* [ms] & $19.7(13.3)$ & $23.2(13.8)$ \\
Liver T2* [ms] & $4.5(4.3)$ & $5.1(4.6)$ \\
LVEDV [mL] & $132.1(33.5)$ & $128.3(38.4)$ \\
LVESV [mL] & $49.3(19.9)$ & $43.8(19.0)$ \\
LVEF [\%] & $59.7(1.8)$ & $66.7(2.3)$ \\
Treatment & & $6(22)$ \\
DFO N (\%) & $10(66.1)$ & $109(52.9)$ \\
$\quad$ DFP N (\%) & $10(9.2)$ & $35(17.0)$ \\
$\quad$ DFX N (\%) & $3(2.75)$ & $6(2.9)$ \\
$\quad$ DFO + DFP N (\%) & $1(0.9)$ & $0(0)$ \\
$\quad$ DFO + DFX N (\%) & & \\
None N (\%) & & \\
\hline
\end{tabular}

shown as mean (SD) except where $\mathrm{N}(\%)$ is shown

LV-left ventricle, EDV-end-diastolic volume, ESV-end-systolic volume, EFejection fraction, DFO-deferoxamine, DFP-deferiprone, DFX-deferasirox.

\section{Statistics}

All statistical analyses were performed by a medical statistician. Two categories of baseline EF were used in this analysis; $56-62 \%$ and $63-70 \%$. These strata were used because $63 \%$ is the lower limit of normal for EF in thalassemia patients in the absence of myocardial siderosis, [19] and 56\% is the lower limit of normal for EF in normal subjects,[21] and patients with EF below this are considered to have definite LV systolic dysfunction or heart failure. Patients were eligible for inclusion in either analysis provided they had one scan with an EF value within the range of either category. All subsequent scans for that patient were then analysed to assess the impact of the change in EF on the outcomes of heart failure. Since only the first scan in a series for each patient was required to be in the specified range, it is possible for patients to be included in both sets of analyses. The association between changes in EF (for each scan after the baseline scan, the change is calculated as the difference between the current scan and the 
baseline) and the outcomes was assessed using a mixedeffects Poisson regression model. Patients were entered as random effects in the model (the random effects are those things that we need to take account of, such as the repeated measures within patients, but which we do not want to estimate, for example we do not want to compare individual patients to one another) with the change in EF entered as a fixed effect (the fixed effect is the predictor variable which we explicitly want to estimate and quantify in terms of its association with the outcome). A p-value of $<0.05$ was taken to be significant, and all analysis was performed using Stata 10.

\section{Results}

A total of 315 patients satisfied the selection inclusion criteria, who had undergone 754 CMR scans. There were $12 \mathrm{HF}$ events in the 56-62\% LVEF cohort and 14 in the $63-70 \%$ LVEF cohort. This equals an event rate of $11.0 \%$ and $6.8 \%$ respectively. Analysis of the occurrence of heart failure showed a relative risk of 0.818 ( $\mathrm{p}<$ 0.001 ) for the stratum of patients with baseline EF 56$62 \%$, which represents an $18.2 \%$ reduction in risk for each $1 \%$ increase in EF (table 2). In the stratum of patients with baseline EF of $63-70 \%$, the relative risk was $0.893(p=0.001)$, which represents a $10.7 \%$ reduction in risk for each $1 \%$ increase in EF. The incremental effect of risk reduction associated with each $1 \%$ increase in EF associated with drug treatment is illustrated in Figure 1. The blue line shows the risk reduction for the group with normal baseline EF, and the red line shows the risk reduction for the group with low baseline EF. The overall risk reduction associated with the improvement in EF for 2 recent treatment trials is illustrated.

\section{Discussion}

Clinical trials of treatment frequently raise the challenging question of whether a statistically significant improvement in a trial endpoint is also clinically meaningful. This can only be addressed by examining the clinical outcomes associated with the improved endpoint, but trials are often designed for a technical outcome of efficacy which may leave them underpowered to directly derive the clinical meaningfulness. Such a situation has arisen in the first randomized clinical trials of oral iron chelation in cardiac siderosis of thalassemia major, where the endpoint of LVEF was shown to be significantly improved with treatment, but the sample size in the trials of approximately 60 patients and the period of follow-up were not sufficient to determine clinical outcomes[8,9]. Under these circumstances an alternative approach to the issue of assessing clinical significance is required. We have approached this issue by examining the clinical outcome of heart failure, with reference to changes over time in EF, in a database of TM patients which has sufficient size to answer outcomes questions. Statistical modelling was applied to a cohort of 315 patients who had at least 2 assessments of LV EF by CMR to establish the relative risk for development of heart failure within 12 months. In order to address the issue of the significance of changes in $\mathrm{EF}$ for patients whose baseline EF was in the normal range for thalassemia major in the absence of cardiac siderosis ( $>63 \%$ ), we formed 2 strata for analysis related to normal ranges of EF, with baseline EF 56-62\% (reduced EF for TM patients) and 63-70\% (lower half of the normal range for TM patients). The results show that an increase in LVEF is associated with statistically significant risk reductions for heart failure for both strata of baseline EF. For a $1 \%$ increase in EF, the risk reduction for heart failure was $18.2 \%$ for the $56-62 \%$ EF stratum, and $10.7 \%$ for the $63-70 \%$ stratum, both of which are of substantial magnitude for such a small absolute change in EF.

These results can then be applied to the findings in 2 comparative cardiac treatment randomized controlled trials (Figure 1) which have been previously reported that have used state of the art measurement of EF with CMR, which is the most reproducible and accurate technique available[21-23]. For the deferiprone monotherapy randomized controlled trial, a statistically significant $3.1 \%$ mean increase in EF was observed in the deferiprone arm[8]. The data from the current study indicate that this degree of mean improvement in EF converts to a mean reduction in risk for development of heart failure of $46.4 \%$ and $29.6 \%$ for patients with a baseline EF of $56-62 \%$ and $63-70 \%$ respectively. For the combination deferiprone-deferoxamine randomised controlled trial, which showed a statistically significant EF increase of $2.6 \%$,[9] the reduction in risk for development of heart failure is $40.7 \%$ and $25.5 \%$ for patients with a baseline EF of $56-62 \%$ and $63-70 \%$ respectively. The large magnitude of these risk reductions in heart failure indicate the statistically significant findings from the randomized controlled trials of deferiprone treatment are in addition, clinically meaningful. The results also indicate that there is a leftward shift in EF that occurs with cardiac iron

Table 2 Relative risk for development of heart failure for each $1 \%$ increase in ejection fraction (EF)

\begin{tabular}{ccccccc}
\hline Baseline ejection fraction & Relative risk & 95\% Confidence intervals & p value & Patients & Scans \\
\hline $56-62 \%$ & 0.818 & 0.767 & 0.872 & $<0.001$ & 109 & 291 \\
\hline $63-70 \%$ & 0.893 & 0.836 & 0.953 & 0.001 & 206 & 463 \\
\hline
\end{tabular}




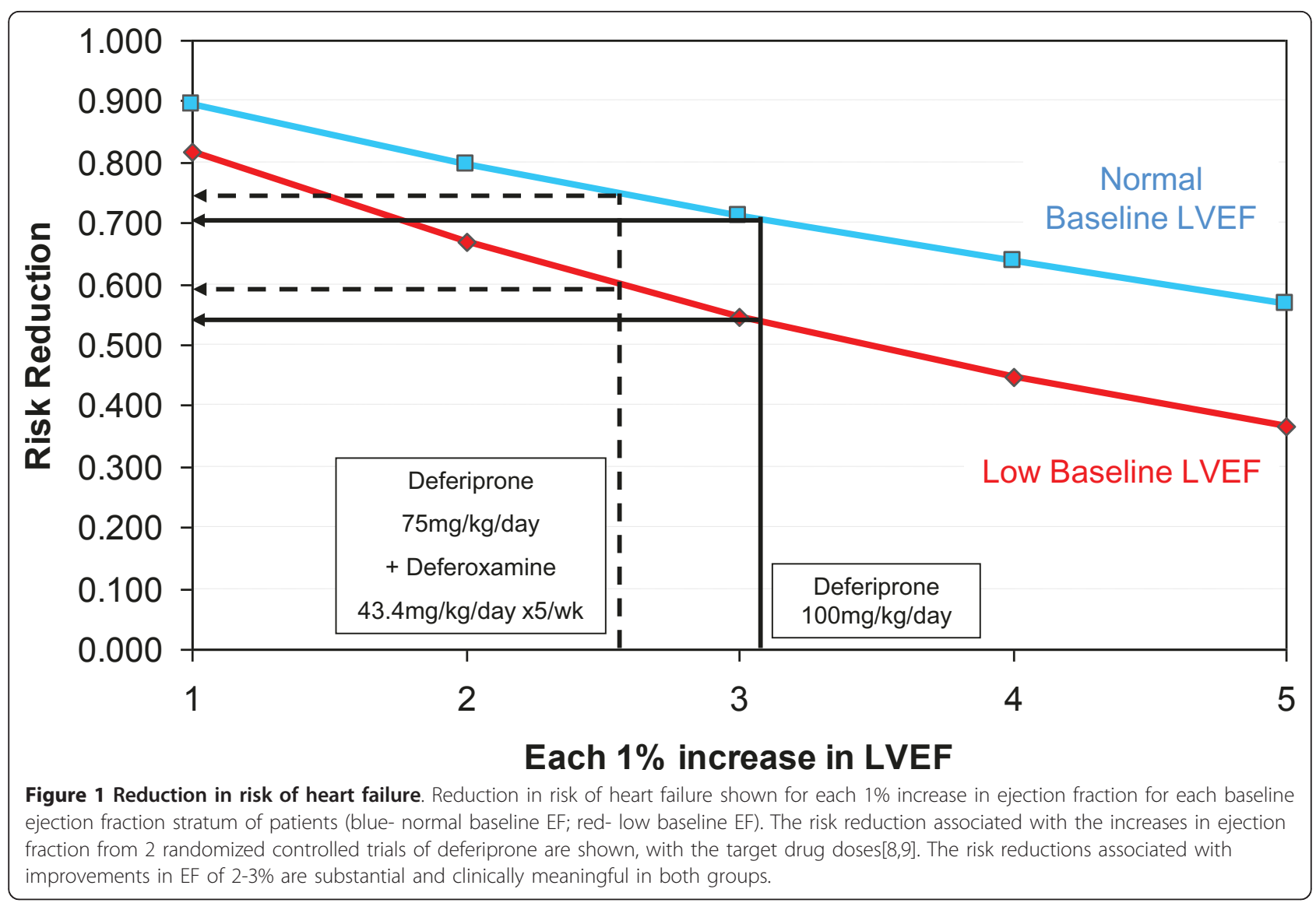

loading, and that prognostically important subclinical $\mathrm{LV}$ dysfunction can be present with EFs in the lower normal range.

Although our analysis indicates significant clinical benefit from the observed improvements in EF seen in the randomized controlled trials of deferiprone, final confirmation can only be obtained from clinical studies comparing iron-induced cardiac morbidity and mortality in transfusion-dependent patients treated with the chelators for long periods of time. Randomized trials examining this question are not viable clinically, and the best alternatives therefore are observational reports of the long-term morbidity and mortality in association with iron chelators. A literature search revealed 6 publications that compared morbidity and mortality in deferiprone-treated and deferoxamine-treated patients. All studies reported significantly less morbidity and/or mortality with deferiprone, but none showed less morbidity or mortality in deferoxamine-treated patients[14,24-28]. Thus the predictions generated from the analyses in this current study are consistent with the clinical outcomes in large observational studies. The improved clinical outcomes are also consistent with the finding of higher EF with chronic deferiprone treatment compared with deferoxamine treatment in a matched cohort study from
Anderson et al [29]. A further relevant study which is consistent with the importance of the EF for cardiac outcomes came from Davis et al, who studied 81 TM patients with no history of heart disease with long-term annual measurement of EF using radionuclide ventriculography[30]. Cardiac death was significantly more common in the patient cohort whose EF was $<45 \%$ or who sustained $>10 \%$ absolute fall in EF between consecutive measurements in comparison with patients whose EF was $>45 \%$ and who had $<10 \%$ absolute fall in EF between consecutive measurements. Although the absolute threshold for abnormal EF is lower for methodological reasons with the legacy radionuclide ventriculography technique than for the now widely available CMR method which was used in the current study, [31] the data of Davis et al confirms the importance of the maintenance of the resting EF in TM, and is in accord with the finding of the current study that a rise of EF is associated with a lower risk of developing heart failure.

Whilst the interpretation of these data indicates that small improvements in EF are associated with meaningful clinical benefits in outcomes, the mechanism of such benefit has not been elucidated. The benefit cannot be due to total body iron reduction, as deferiprone is no 
more effective than deferoxamine in this action [8]. There are also no data to indicate that deferiprone has any clinically significant inotropic or vasodilator effects, and thus it is unlikely that clinical benefit accrues from a primary effect on enhancing myocardial contractility or changing dynamics of vascular flow. On the other hand, the data do provide evidence of increased cardiac performance, as measured by changes in LVEF. Thus it is reasonable to consider mechanisms that might enhance contractility in a heart that is beginning to fail in patients with transfusional iron overload, and which could be altered by the administration of an iron chelator like deferiprone.

Considering possible mechanisms that might enhance contractility in the failing heart of patients with transfusional iron overload we can draw some analogies with recent findings in Friedreich's Ataxia, particularly the association of cardiac abnormalities with excessive mitochondrial iron accumulation and their correction by iron chelation [32]. We hypothesize that iron-mediated damage of the heart, as reflected in LV function in iron overload, is associated with heart cell mitochondria[33]. The endosymbiont mitochondria with their own DNA are subcellular organelles which distinguish eukaryotic from prokaryotic cells, and drive the cellular bioenergetics responsible for the genomic complexity that has permitted the evolution of multicellular organisms[34]. Mitochondria generate cellular energy in a biologically useful form in the form of adenosine triphosphate (ATP), and in the healthy human heart, mitochondria harness more than $90 \%$ of cell ATP production via oxidative phosphorylation[35]. In disease states such as heart failure,[36] the mitochondrial oxidative capacity of cardiac muscle cells may be diminished,[37-43] and consequently the contractile performance of the failing heart may be limited. In systemic iron overload, mitochondria are the major cellular sites of toxic iron accumulation, [44] and it is therefore sensible to consider mitochondrial "toxic iron" as a major pathophysiological factor and an important target for iron chelation[45]. Evidence that heart failure in chronic iron overload may be largely due to mitochondrial damage [46] was obtained in mice injected with iron dextran over 4 weeks[47]. These animals showed various pathophysiological changes due to chronic iron-induced organ toxicity, including cardiomyopathy: a) total cardiac iron was increased almost 10-fold, which is similar in magnitude to that reported at autopsy in hearts of TM patients who had died of heart failure [2]; b) iron analysis revealed approximately a $50 \%$ increase in extractable (trichloroacetic acid-soluble) cardiac iron in ironinjected animals; c) both biochemical and electron microscopy analyses revealed extensive damage to mitochondria in myocytes of iron-treated mice. The loss of mitochondrial respiratory capacity and ensuing cardiac dysfunction were attributed to decreased expression of mitochondria encoded mRNA and proteins due to mitochondrial DNA damage[47].

This leads to the question of why the heart is particularly sensitive to excessive iron loading compared to other tissues of polytransfused patients, which, in fact, might accumulate even larger amounts of the metal. The heart may be particularly sensitive to iron-induced mitochondrial damage relative to other tissues because of the large number of mitochondria which are required for its high respiratory requirements, and its low level of antioxidants[48]. Mitochondria generate ATP as a result of the action of 5 respiratory chain complexes,[49] and it has been estimated that the human heart creates $6 \mathrm{~kg}$ of ATP daily for its metabolic needs[50,51]. In human heart, deranged high energy phosphate metabolism is detectable in heart failure and is a predictor of mortality [52]. In rat heart cells, iron exposure reduced enzyme complex activity by up to $65 \%$, which resulted in approximately a $25 \%$ drop in ATP production[49]. Contractility is probably downregulated in response to the reduced ATP production, and steady state ATP levels are maintained until a more end-stage situation. Respiratory chain inhibition could result from 4 main mechanisms: First, iron exposure increases the generation of toxic reactive oxygen species (ROS),[53] especially hydroxyl radicals, [54] which can lead to peroxidation of lipid components of the mitochondrial membrane such as cardiolipin, and impairment of respiratory chain complex assembly and activity;[55,56] Second, peroxidation of polyunsaturated fatty acids can lead to covalent protein linking which alters enzyme activity;[57] Third, iron may bind directly to respiratory chain enzymes and create active oxygen species which convert amino acid residues to carbonyl derivatives that reduce catalytic activity and increase protein degradation;[58] Fourth, ROS cause cumulative damage to mitochondrial DNA, reduced mitochondrial mRNA and impaired synthesis of respiratory chain subunits coded by the mitochondria, whereas subunits coded by nuclear DNA are unaffected[33,47]. A vicious cycle may be created where the respiratory chain enzymes may undergo oxidative inactivation which may lead to incomplete reduction of molecular oxygen and increased formation of free radicals[59]. ROS and mitochondrial dysfunction have also been linked to activation of the NLRP3 inflammasome, which is a molecular platform that triggers innate immunity and pro-inflammatory cytokines [60]. ROS also cause opening of the mitochondrial permeability transition pore, which can lead to cardiomyocyte apoptosis $[61,62]$. These cellular and systemic mechanisms associated with iron and redox 
dyshomeostasis might underlie the catastrophic deterioration in cardiac function that occurs as a terminal event in thalassemia major patients with heart failure.

Regardless of which of the above mechanisms is primarily responsible for most of the iron-ROS evoked damage in transfusional iron overload, improving EF and meeting the high metabolic demands for increased cardiac muscle contraction would depend on the ability to restore mitochondrial activities and thereby improve myocardial cell function. As increased cell labile iron levels might play a key role in the pathophysiology of heart failure,[63] a rational approach for treating cardiac iron overload would entail reduction of intracellular labile iron levels. An ideal iron chelating agent for this would readily cross cellular and subcellular membranes, and have an adequate affinity for specifically binding labile iron while forming non-redox active iron complexes that can also exit cells but also minimally interfere with resident cell activities, particularly those that are iron-dependent. Among the chelators in clinical use, deferiprone was found to optimally meet the above criteria in a frataxin-deficient HEK-293 cell model of mitochondrial iron accumulation [64]. Recent trials with deferiprone on Friedriech's ataxia patients indicate that such a modus operandi might also be operative in the clinical setting of hypertrophic cardiomyopathy observed in these patients[32].

The three clinically available iron chelators, deferoxamine, deferiprone and deferasirox all remove iron from the body, but display different efficacy in removing iron from different organs. Some of these differences are attributable to their different chemical structures that confer them with different chemical and physicochemical properties resulting in different bioavailability, pharmacokinetics and tissue distribution including accessibility to cellular labile iron pools [65-67]. The small molecular weight bidentate deferiprone, combined with its neutral charge and optimal partition coefficient displays greater ability to permeate membranes, $[68,69]$ and remove iron from the myocardium than the much larger, charged hexadentate deferoxamine molecule[70]. The recently reported longitudinal 12 month trial of deferasirox in asymptomatic myocardial siderosis also showed good cardiac iron removal, but with an absence of improvement in LVEF,[11] with both effects persisting to 2 years,[71] and 3 years[72]. These results were very similar to those found in the US04 study[73,74].

Possible differences in the mode of action of deferiprone versus deferasirox might relate to a differential drug accessibility to labile iron pools within cells (particularly within mitochondria) or with an intrinsic ability of a chelator to associate with cell components such as membranes or proteins and thereby become retained in cells. Prolonged retention in cells can also be deleterious as a chelator can interfere with the biosynthetic machinery of heme or iron-S-clusters, and in extreme conditions could drive cells into an apoptotic path[75-77]. On the other hand, intermittent application of high doses of deferasirox to aged animals on alternate days was not only effective in reducing age related iron accumulation but also iron-mediated cell apoptosis[78]. One can argue that a relatively short time of tissue exposure to a chelator might limit iron chelation efficacy in the organism. However, relatively short exposures might also be advantageous as possible interferences with essential iron-dependent processes are also reduced. We propose that this "kiss-and-go" modality of chelation might be appropriate for removing iron that slowly accumulates in particular cell compartments until reaching toxic levels, as supported by basic and clinical data[64,79-81]. Further investigation of these possibilities is required to explain the intriguing differences in ejection fraction responses among the iron chelators. Whilst further basic science studies will undoubtedly be helpful in this mechanistic dissection, newer clinical trials may also yield clues. For example, as clinical experience grows in combining deferasirox with deferiprone for patient treatment, [82] it would be interesting to identify whether this combination is better, similar or worse at improving LVEF in patients with stable chronic cardiac iron loading than deferiprone in isolation.

\section{Conclusion}

Analysis of a large TM database showed that small changes in ejection fraction have statistically significant and clinically meaningful effects in reducing the important clinical outcome of heart failure. These data suggest that the results from randomized controlled trials using deferiprone in TM yield a $40.7 \%$ to $46.4 \%$ relative risk reduction for heart failure in patients with a baseline ejection fraction below normal of 56-62\%, and a $25.5 \%$ to $29.6 \%$ relative risk reduction for heart failure in patients with normal baseline ejection fraction of $63-70 \%$. These predicted improved outcomes are consistent with several reports of reduced heart disease and increased survival in transfusion-dependent patients treated with deferiprone, lending support to the predictive value of improvement in clinical outcome as a consequence of increasing LVEF. The data indicate that prognostically important subclinical LV dysfunction can occur in TM patients with cardiac iron overload whilst EF remains in the lower normal range. The most likely explanation for the improvement in LV function found in the randomized controlled trials using deferiprone, is improved myocardial mitochondrial function although the exact mechanisms remain to be fully elucidated. 


\section{Acknowledgements}

We would like to thank Stefan Neubauer for assistance in the discussion about ATP, and Alexander Lyon for assistance in discussion of mitochondria. This work was supported by the National Institutes for Health Research Cardiovascular Biomedical Research Unit of Royal Brompton and Harefield NHS Foundation Trust and Imperial College.

\section{Author details}

'Cardiovascular Magnetic Resonance Unit, Royal Brompton Hospital, London UK. ${ }^{2}$ National Heart and Lung Institute, Imperial College, London UK. ${ }^{3}$ Department of Statistics, University College London, UK. ${ }^{4}$ Life Sciences Institute, Hebrew University of Jerusalem, Safra Campus-Givat Ram, Jerusalem, Israel.

\section{Authors' contributions}

DJP conceived the study and wrote the manuscript. JPC was responsible for data collection. MR performed the statistical analysis. IZC assisted in interpretation of the results and basic science discussion of mitochondria. All authors read and approved the final manuscript.

\section{Competing interests}

Dr Pennell is a consultant to Siemens, Novartis and Apotex, and has received research support and speaker's honoraria. He is a director of Cardiovascular Imaging Solutions. John-Paul Carpenter and Michael Roughton have no conflicts to declare. Dr Cabantchik has received research support and speaker's honoraria from Novartis and Apotex.

Received: 6 September 2011 Accepted: 12 September 2011 Published: 12 September 2011

\section{References}

1. Anderson LJ, Holden S, Davis B, Prescott E, Charrier CC, Bunce NH, Firmin DN, Wonke B, Porter J, Walker JM, Pennell DJ: Cardiovascular T2-star (T2*) magnetic resonance for the early diagnosis of myocardial iron overload. Eur Heart J 2001, 23:2171-9.

2. Carpenter JP, He T, Kirk P, Roughton M, Anderson LJ, de Noronha SV, Sheppard MN, Porter JB, Walker JM, Wood JC, Galanello R, Forni G, Catani G, Matta G, Fucharoen S, Fleming A, House MJ, Black G, Firmin DN, St Pierre TG, Pennell DJ: On T2* magnetic resonance and cardiac iron. Circulation 2011, 123:1519-28.

3. Tanner MA, Galanello R, Dessi C, Westwood MA, Smith GC, Nair SV, Anderson $L$, Walker $J M$, Pennell DJ: Myocardial iron loading in patients with thalassemia major on deferoxamine chelation. J Cardiovasc Magn Reson 2006, 8:543-7.

4. Daar S, Pathare AV, Jain R, Zadjali SA, Pennell DJ: T2* cardiovascular magnetic resonance in the management of thalassemia patients in Oman. Haematologica 2009, 94:140-1.

5. Tanner MA, Galanello R, Dessi C, Westwood MA, Smith GC, Nair SV Anderson $L$, Walker JM, Pennell DJ: Myocardial iron loading in patients with thalassemia major on deferoxamine chelation. J Cardiovasc Magn Reson 2006, 8:543-7.

6. Chouliaras GL, Kattamis A, Berdoukas V, Gotsis ED, Mavrogeni S, Ladis V: Cardiac magnetic resonance in transfusion dependent thalassaemia: assessment of iron load and relationship to left ventricular ejection fraction. Br J Haematol 2010, 151:397-401.

7. Marsella M, Borgna-Pignatti C, Meloni A, Caldarelli V, Dell'Amico MC, Spasiano A, Pitrolo L, Cracolici E, Valeri G, Positano V, Lombardi M, Pepe A: Cardiac iron and cardiac disease in males and females with transfusiondependent thalassemia major: a T2* magnetic resonance imaging study. Haematologica 2011, 96:515-20

8. Pennell DJ, Berdoukas V, Karagiorga M, Ladis V, Piga A, Aessopos A, Gotsis ED, Tanner MA, Smith GC, Westwood MA, Wonke B, Galanello R: Randomized controlled trial of deferiprone or deferoxamine in betathalassemia major patients with asymptomatic myocardial siderosis. Blood 2006, 107:3738-44.

9. Tanner MA, Galanello R, Dessi C, Smith GC, Westwood MA, Agus A, Roughton M, Assomull R, Nair SV, Walker JM, Pennell DJ: A randomized, placebo controlled, double blind trial of the effect of combined therapy with deferoxamine and deferiprone on myocardial iron in thalassemia major using cardiovascular magnetic resonance. Circulation 2007, 115:1876-84.
10. Tanner MA, Galanello R, Dessi C, Smith GC, Westwood MA, Agus A, Pibiri M, Nair SV, Walker JM, Pennell DJ: Combined chelation therapy in thalassemia major for the treatment of severe myocardial siderosis with left ventricular dysfunction. J Cardiovasc Magn Reson 2008, 10:12

11. Pennell DJ, Porter JB, Cappellini MD, El-Beshlawy A, Chan LL, Aydinok Y, Elalfy MS, Sutcharitchan P, Li CK, Ibrahim H, Viprakasit V, Kattamis A, Smith G, Habr D, Domokos G, Roubert B, Taher A: Efficacy of deferasirox in reducing and preventing cardiac iron overload in beta-thalassemia. Blood 2010, 115:2364-71.

12. Berdoukas V, Chouliaras G, Moraitis P, Zannikos P, Berdoussi E, Ladis V: The efficacy of iron chelator regimes in reducing cardiac and hepatic iron in patients with thalassaemia major: a clinical observational study. $J$ Cardiovasc Magn Reson 2009, 11:20.

13. Borgna-Pignatti C, Cappellini MD, De Stefano P, Del Vecchio GC, Forni GL, Gamberini MR, Ghilardi R, Piga A, Romeo MA, Zhao H, Cnaan A: Cardiac morbidity and mortality in deferoxamine- or deferiprone-treated patients with thalassemia major. Blood 2006, 107:3733-7.

14. Modell B, Khan M, Darlison M, Westwood MA, Ingram D, Pennell DJ: Improved survival of thalassaemia major in the UK and relation to $\mathrm{T}^{*}$ * cardiovascular magnetic resonance. J Cardiovasc Magn Reson 2008, 10:42.

15. Telfer PT, Warburton F, Christou S, Hadjigavriel M, Sitarou M, Kolnagou A, Angastiniotis M: Improved survival in thalassemia major patients on switching from desferrioxamine to combined chelation therapy with desferrioxamine and deferiprone. Haematologica 2009, 94:1777-8.

16. Anderson $\sqcup$, Westwood MA, Holden S, Davis B, Prescott E, Wonke B, Porter JB, Walker JM, Pennell DJ: Myocardial iron clearance during reversal of siderotic cardiomyopathy with intravenous desferrioxamine: a prospective study using $\mathrm{T}^{*}$ cardiovascular magnetic resonance. $\mathrm{Br} J$ Haematol 2004, 127:348-55.

17. Kremastinos DT, Tsetsos GA, Tsiapras DP, Karavolias GK, Ladis VA, Kattamis CA: Heart failure in beta thalassemia: a 5-year follow-up study. Am J Med 2001, 111:407-8.

18. Kirk P, Roughton M, Porter JB, Walker JM, Tanner MA, Patel J, Wu D, Taylor J, Westwood MA, Anderson L, Pennell DJ: Cardiac T2* magnetic resonance for prediction of cardiac complications in thalassemia major Circulation 2009, 120:1961-8.

19. Westwood MA, Anderson LJ, Maceira AM, Shah FT, Prescott E, Porter JB, Wonke B, Walker JM, Pennell DJ: Normalized left ventricular volumes and function in thalassemia major patients with normal myocardial iron. $J$ Magn Reson Imaging 2007, 25:1147-51.

20. Westwood M, Anderson L, Firmin DN, Gatehouse PD, Charrier CC, Wonke B, Pennell DJ: A single breath-hold multiecho $\mathrm{T}^{*}$ cardiovascular magnetic resonance technique for diagnosis of myocardial iron overload. J Magn Reson Imaging 2003, 18:33-9.

21. Maceira AM, Prasad SK, Khan M, Pennell DJ: Normalized left ventricular systolic and diastolic function by steady state free precession cardiovascular magnetic resonance. J Cardiovasc Magn Reson 2006, 8:417-26.

22. Grothues F, Smith GC, Moon JCC, Bellenger NG, Collins P, Klein H, Pennell DJ: Comparison of interstudy reproducibility of cardiovascular magnetic resonance with two-dimensional echocardiography in normal subjects and in patients with heart failure or left ventricular hypertrophy. Am J Cardiol 2002, 90:29-34.

23. Maceira AM, Bellenger NG, Pennell DJ: Assessment of cardiac function. In Cardiovascular magnetic resonance.. 2 edition. Edited by: Manning WJ, Pennell DJ. Churchill Livingstone, Philadelphia, USA; 2010:

24. Piga A, Gaglioti C, Fogliacco E, Tricta F: Comparative effects of deferiprone and deferoxamine on survival and cardiac disease in patients with thalassemia major: a retrospective analysis. Haematologica 2003, 88:489-96

25. Borgna-Pignatti C, Cappellini MD, De Stefano P, Del Vecchio GC, Forni GL, Gamberini MR, Ghilardi R, Piga A, Romeo MA, Zhao H, Cnaan A: Cardiac morbidity and mortality in deferoxamine- or deferiprone-treated patients with thalassemia major. Blood 2006, 107:3733-7.

26. Ceci A, Baiardi P, Catapano M, Felisi M, Cianciulli P, De Sanctis V, Del Vecchio GC, Magnano C, Meo A, Maggio A: Risk factors for death in patients with beta-thalassemia major: results of a case-control study. Haematologica 2006, 91:1420-1.

27. Telfer PT, Warburton F, Christou S, Hadjigavriel M, Sitarou M, Kolnagou A, Angastiniotis M: Improved survival in thalassemia major patients on 
switching from desferrioxamine to combined chelation therapy with desferrioxamine and deferiprone. Haematologica 2009, 94:1777-8.

28. Maggio A, Vitrano A, Capra M, Cuccia L, Gagliardotto F, Filosa A, Magnano C, Rizzo M, Caruso V, Gerardi C, Argento C, Campisi S, Cantella F, Commendatore F, D'Ascola DG, Fidone C, Ciancio A, Galati MC, Giuffrida G, Cingari R, Giugno G, Lombardo T, Prossomariti L, Malizia R, Meo A, Roccamo G, Romeo MA, Violi P, Cianciulli P, Rigano P: Improving survival with deferiprone treatment in patients with thalassemia major: a prospective multicenter randomised clinical trial under the auspices of the Italian Society for Thalassemia and Hemoglobinopathies. Blood Cells Mol Dis 2009, 42:247-51.

29. Anderson LJ, Wonke B, Prescott E, Holden S, Walker JM, Pennell DJ: Comparison of effects of oral deferiprone and subcutaneous desferrioxamine on myocardial iron concentrations and ventricular function in beta-thalassaemia. Lancet 2002, 360:516-20.

30. Davis BA, O'Sullivan C, Jarritt PH, Porter JB: Value of sequential monitoring of left ventricular ejection fraction in the management of thalassemia major. Blood 2004, 104:263-9.

31. Bellenger NG, Burgess MI, Ray SG, Lahiri A, Coats AJ, Pennell DJ, CHRISTMAS Study Steering Committee and Investigators: Comparison of left ventricular ejection fraction and volumes in heart failure by echocardiography, radionuclide ventriculography and cardiovascular magnetic resonance Are they interchangeable? Eur Heart J 2000, 21:1387-96.

32. Velasco-Sánchez $D$, Aracil $A$, Montero R, Mas A, Jiménez L, O'Callaghan M, Tondo M, Capdevila A, Blanch J, Artuch R, Pineda M: Combined therapy with idebenone and deferiprone in patients with Friedreich's ataxia. Cerebellum 2011, 10:1-8.

33. Gao X, Qian M, Campian JL, Marshall J, Zhou Z, Roberts AM, Kang YJ, Prabhu SD, Sun XF, Eaton JW: Mitochondrial dysfunction may explain the cardiomyopathy of chronic iron overload. Free Radic Biol Med 2010, 49:401-7.

34. Lane N, Martin W: The energetics of genome complexity. Nature 2010, 467:929-34.

35. Stanley WC, Recchia FA, Lopaschuk GD: Myocardial substrate metabolism in the normal and failing heart. Physiol Rev 2005, 85:1093-129.

36. Garnier A, Fortin D, Delomenie C, Momken I, Veksler V, Ventura-Clapier R: Depressed mitochondrial transcription factors and oxidative capacity in rat failing cardiac and skeletal muscles. J Physiol 2003, 551:491-501.

37. Montgomery C, Hamilton N, lanuzzo CD: Energy status of the rapidly paced canine myocardium in congestive heart failure. J Appl Physiol 1992, 73:2363-7.

38. Neubauer $\mathrm{S}$, Krahe T, Schindler R, Horn M, Hillenbrand H, Entzeroth $\mathrm{C}$, et al: 31P magnetic resonance spectroscopy in dilated cardiomyopathy and coronary artery disease. Altered cardiac high-energy phosphate metabolism in heart failure. Circulation 1992, 86:1810-8.

39. Zhang J, Merkle H, Hendrich K, Garwood M, From AH, Ugurbil K, Bache RJ: Bioenergetic abnormalities associated with severe left ventricular hypertrophy. J Clin Invest 1993, 92:993-1003.

40. Feygin J, Mansoor A, Eckman P, Swingen C, Zhang J: Functional and bioenergetic modulations in the infarct border zone following autologous mesenchymal stem cell transplantation. Am J Physiol Heart Circ Physiol 2007, 293:H1772-80.

41. Liao R, Nascimben L, Friedrich J, Gwathmey JK, Ingwall JS: Decreased energy reserve in an animal model of dilated cardiomyopathy. Relationship to contractile performance. Circ Res 1996, 78:893-902.

42. Murakami Y, Zhang Y, Cho YK, Mansoor AM, Chung JK, Chu C, Francis G, Ugurbil K, Bache RJ, From AH, Jerosch-Herold M, Wilke N, Zhang J: Myocardial oxygenation during high work states in hearts with postinfarction remodeling. Circulation 1999, 99:942-8.

43. Jung WI, Sieverding L, Breuer J, Hoess T, Widmaier S, Schmidt O, Bunse M, van Erckelens F, Apitz J, Lutz O, Dietze GJ: 31P NMR spectroscopy detects metabolic abnormalities in asymptomatic patients with hypertrophic cardiomyopathy. Circulation 1998, 97:2536-42.

44. Link G, Saada A, Pinson A, Konijn AM, Hershko C: Mitochondrial respiratory enzymes are a major target of iron toxicity in rat heart cells. $J$ Lab Clin Med 1998, 131:466-74.

45. Hershko C, Link G, Cabantchik Zl: Pathophysiology of Iron Overload. Ann NY Acad Sci 2006, 850:191-201.

46. Kuryshev YA, Brittenham GM, Fujioka H, Kannan P, Shieh CC, Cohen SA, Brown AM: Decreased sodium and increased transient outward potassium currents in iron-loaded cardiac myocytes implications for the arrhythmogenesis of human siderotic heart disease. Circulation 1999, 100:675-83.

47. Gao X, Campian JL, Qian M, Sun XF, Eaton JW: Mitochondrial DNA damage in iron overload. J Biol Chem 2009, 284:4767-75.

48. Lesnefsky EJ, Moghaddas S, Tandler B, Kerner J, Hoppel CL: Mitochondrial dysfunction in cardiac disease: ischemia-reperfusion, aging, and heart failure. J Mol Cell Cardiol 2001, 33:1065-89.

49. Link G, Saada A, Pinson A, Konijn AM, Hershko C: Mitochondrial respiratory enzymes are a major target of iron toxicity in rat heart cells. J Lab Clin Med 1998, 131:466-74.

50. Ingwall JS: ATP and the heart. Kluwer Academic Publishers. Norwell, Massachusetts, USA; 2002, 16, ISBN 1-4020-7093-4.

51. Neubauer S: The failing heart-an engine out of fuel. N Engl J Med 2007, 356:1140-51.

52. Neubauer S, Horn M, Cramer M, Harre K, Newell JB, Peters W, Pabst T, Ertl G, Hahn D, Ingwall JS, Kochsiek K: Myocardial phosphocreatine-to-ATP ratio is a predictor of mortality in patients with dilated cardiomyopathy. Circulation 1997, 96:2190-6.

53. Eaton JW, Qian M: Molecular bases of cellular iron toxicity. Free Radic Biol Med 2002, 32:833-40

54. Kadiiska MB, Burkitt MJ, Xiang QH, Mason RP: Iron supplementation generates hydroxyl radical in vivo. An ESR spin-trapping investigation. $J$ Clin Invest 1995, 96:1653-7.

55. Fry M, Green DE: Cardiolipin requirement by cytochrome oxidase and the catalytic role of phospholipid. Biochem Biophys Res Commun 1980, 93:1238-46.

56. Goormaghtigh E, Brasseur R, Ruysschaert JM: Adriamycin inactivates cytochrome $\mathrm{c}$ oxidase by exclusion of the enzyme from its cardiolipin essential environment. Biochem Biophys Res Commun 1982, 104:314-20.

57. Houglum K, Filip M, Witztum JL, Chojkier M: Malondialdehyde and 4hydroxynonenal protein adducts in plasma and liver of rats with iron overload. J Clin Invest 1990, 86:1991-8.

58. Stadtman ER: Metal ion-catalyzed oxidation of proteins: biochemical mechanism and biological consequences. Free Radic Biol Med 1990, 9:315-25.

59. Pitkanen S, Robinson BH: Mitochondrial complex I deficiency leads to increased production of superoxide radicals and induction of superoxide dismutase. J Clin Invest 1996, 98:345-51.

60. Zhou R, Yazdi AS, Menu P, Tschopp J: A role for mitochondria in NLRP3 inflammasome activation. Nature 2011, 469:221-5.

61. Gustafsson AB, Gottlieb RA: Heart mitochondria: gates of life and death. Cardiovasc Res 2008, 77:334-43.

62. Lyon AR, Joudrey PJ, Jin D, Nass RD, Aon MA, O'Rourke B, Akar FG: Optical imaging of mitochondrial function uncovers actively propagating waves of mitochondrial membrane potential collapse across intact heart. $J \mathrm{Mol}$ Cell Cardiol 2010, 49:565-75.

63. Wood JC, Glynos T, Thompson A, Giardina P, Harmatz P, Kang BP, Paley C, Coates TD: Relationship between labile plasma iron, liver iron concentration and cardiac response in a deferasirox monotherapy trial. Haematologica 2011, 96:1055-8.

64. Kakhlon O, Manning H, Breuer W, Melamed-Book N, Lu C, Cortopassi G, Munnich A, Cabantchik Zl: Cell functions impaired by frataxin deficiency are restored by drug-mediated iron relocation. Blood 2008, 112:5219-27.

65. Galanello R: Deferiprone in the treatment of transfusion-dependent thalassemia: a review and perspective. Ther Clin Risk Manag 2007, 3:795-805.

66. Waldmeier F, Bruin GJ, Glaenzel U, Hazell K, Sechaud R, Warrington S, Porter JB: Pharmacokinetics, metabolism, and disposition of deferasirox in beta-thalassemic patients with transfusion-dependent iron overload who are at pharmacokinetic steady state. Drug Metab Dispos 2010, 38:808-16.

67. Porter JB: Deferoxamine pharmacokinetics. Semin Hematol 2001, 38(Suppl 1):63-8.

68. Shalev O, Repka T, Goldfarb A, Grinberg L, Abrahamov A, Olivieri NF, Rachmilewitz EA, Hebbel RP: Deferiprone (L1) chelates pathologic iron deposits from membranes of intact thalassemic and sickle red blood cells both in vitro and in vivo. Blood 1995, 86:2008-13.

69. De Franceschi L, Shalev O, Piga A, Collell M, Olivieri O, Corrocher R, Hebbel RP, Brugnara C: Deferiprone therapy in homozygous human beta- 
thalassemia removes erythrocyte membrane free iron and reduces $\mathrm{KCl}$ cotransport activity. J Lab Clin Med 1999, 133:64-9.

70. Galanello R, Campus S: Deferiprone chelation therapy for thalassemia major. Acta Haematol 2009, 122:155-64.

71. Pennell DJ, Porter JB, Cappellini MD, Chan LL, El-Beshlawy A, Aydinok Y, Ibrahim H, Li CK, Viprakasit V, Elalfy MS, Kattamis A, Smith G, Habr D, Domokos G, Roubert B, Taher A: Continued improvement in myocardial T2* over 2 years of deferasirox therapy in beta-thalassemia major patients with cardiac iron overload. Haematologica 2011, 96:48-54.

72. Pennell D, Porter JB, Cappellini MD, Chan LL, El-Beshlawy A, Aydinok Y, Ibrahim H, Li CK, Viprakasit V, Elalfy MS, Kattamis A, Smith G, Habr D, Domokos $G$, Roubert B, Taher A: Continued improvement and normalization of myocardial T2* in patients with $\beta$ thalassemia major treated with Deferasirox (Exjade ${ }^{\oplus}$ ) for up to 3 years. Blood 2010, 116: abstract 4276 .

73. Wood JC, Kang BP, Thompson A, Giardina P, Harmatz P, Glynos T, Paley C, Coates TD: The effect of deferasirox on cardiac iron in thalassemia major: impact of total body iron stores. Blood 2010, 116:537-43.

74. Wood JC, Glynos T, Thompson A, Giardina P, Harmatz P, Kang BP, Paley C, Coates TD: Follow-up report on the 2-year cardiac data from a deferasirox monotherapy trial. Am J Hematol 2010, 85:818-9.

75. Hileti $D$, Panayiotidis $P$, Hoffbrand $A V$ : Iron chelators induce apoptosis in proliferating cells. Br J Haematol 1995, 89:181-7.

76. Kim BS, Yoon KH, Oh HM, Choi EY, Kim SW, Han WC, Kim EA, Choi SC, Kim TH, Yun KJ, Kim EC, Lyou JH, Nah YH, Chung HT, Cha YN, Jun CD: Involvement of p38 MAP kinase during iron chelator-mediated apoptotic cell death. Cell Immunol 2002, 220:96-106.

77. Choi SC, Kim BS, Song MY, Choi EY, Oh HM, Lyou JH, Han WC, Moon HB, Kim TH, Oh JM, Chung HT, Jun CD: Downregulation of p38 kinase pathway by CAMP response element-binding protein protects $\mathrm{HL}-60$ cells from iron chelator-induced apoptosis. Free Radic Biol Med 2003, 35:1171-84.

78. Arvapalli RK, Paturi S, Laurino JP, Katta A, Kakarla SK, Gadde MK, Wu M, Rice KM, Walker EM, Wehner P, Blough ER: Deferasirox decreases ageassociated iron accumulation in the aging F344XBN rat heart and liver. Cardiovasc Toxicol 2010, 10:108-16.

79. Kakhlon O, Breuer W, Munnich A, Cabantchik ZI: Ion redistribution as a therapeutic strategy for treating diseases of localized iron accumulation. Can Physiol Pharmacol 2010, 88:187-96.

80. Sohn YS, Mitterstiller AM, Breuer W, Weiss G, Cabantchik ZI: Rescuing ironoverloaded macrophages by conservative relocation of the accumulated metal. Br J Pharmacol 2011, 164:406-18.

81. Gaboriau F, Leray AM, Ropert M, Gouffier L, Cannie I, Troadec MB, Loréal O, Brissot $P$, Lescoat $G$ : Effects of deferasirox and deferiprone on cellular iron load in the human hepatoma cell line HepaRG. Biometals 2010, 23:231-45.

82. Voskaridou E, Christoulas D, Terpos E: Successful chelation therapy with the combination of deferasirox and deferiprone in a patient with thalassaemia major and persisting severe iron overload after singleagent chelation therapies. Br J Haematol 2011, 154:654-6.

doi:10.1186/1532-429X-13-45

Cite this article as: Pennell et al:: On improvement in ejection fraction with iron chelation in thalassemia major and the risk of future heart failure. Journal of Cardiovascular Magnetic Resonance 2011 13:45.

\section{Submit your next manuscript to BioMed Central and take full advantage of:}

- Convenient online submission

- Thorough peer review

- No space constraints or color figure charges

- Immediate publication on acceptance

- Inclusion in PubMed, CAS, Scopus and Google Scholar

- Research which is freely available for redistribution

Submit your manuscript at www.biomedcentral.com/submit
Biomed Central 